\title{
Relação: mídias com ensino aprendizagem
}

\author{
(Relationship: media with teaching learning) \\ Marlene de Oliveira \\ Universidad Tecnológica Intercontinental, UTIC (Paraguay) \\ marleneforster2@gmail.com
}

Fecha recepción: 21-03-2019

Páginas: $64-73$

Fecha aceptación: 20-05-2019

\section{Resumo.}

Este artigo trata-se sobre as Mídias no Processo Ensino Aprendizagem com o objetivo de descrever a incorporação das mídias na pratica docente e os benefícios para o processo ensino aprendizagem do primeiro, segundo e terceiro ano do ensino fundamental da Escola Municipal de Educação Básica Maria Aparecida Amaro de Souza. Para a realização deste trabalho fez-se necessário uma pesquisa e analise sobre a questão levantada, tanto no campo pratico quanto o bibliográfico. Fez-se a investigação com enfoque qualitativo, no nível descritivo com o esboço não experimental visando-se detalhar os procedimentos de execução do trabalho. As técnicas e instrumentos foram aplicados aos educadores do ensino fundamental sendo aplicado um questionário contendo quinze questões e utilizou-se de uma ficha guia para observação contendo seis itens a serem observados. A investigação fundamentalmente apresenta planejamento do problema, os objetivos da investigação, seguido do desenvolvimento do marco teórico e analise e interpretação dos dados coletado se finalmente as conclusões e recomendações. Neste contexto considera-se que os educadores proporcionem interesses e habilidades na incorporação das mídias tecnológicas e reconhecem-se os benefícios das mídias para o processo ensino aprendizagem.

Palavras-chave: mídia; processo ensino aprendizagem; incorporação das mídias; pratica docente

\begin{abstract}
.
This article deals with the Media in the Teaching Learning Process with the purpose of describing the incorporation of the media in the teaching practice and the benefits to the process teaching teaching of the first, second and third year of elementary school of the Municipal School of Basic Education Maria Aparecida Amaro de Souza. For the accomplishment of this work it became necessary to research and analyze on the question raised, both in the practical and bibliographic field. The research was carried out with a qualitative approach, at the descriptive level with the non-experimental sketch, aiming at detailing the procedures for performing the work. The techniques and instruments were applied to elementary school educators and a questionnaire containing fifteen questions was applied and a guide sheet was used for observation containing six items to be observed. Research fundamentally presents problem planning, research objectives, followed by the development of the theoretical framework and analysis and interpretation of the data collected if finally the conclusions and recommendations. In this context, it is considered that educators provide interests and skills in the incorporation of technological media and recognize the benefits of media for the teaching-learning process.
\end{abstract}

Key words: media; teaching learning process; incorporation of the media; practice teacher 


\section{1.-Introdução.}

Este trabalho tem como tema Relação: Mídias com Ensino Aprendizagem pensandose numa sociedade onde ocorrem mudanças tecnológicas cada vez mais velozes e indispensáveis para o ser humano, e consequentemente nos depararam com as necessidades da reorganização das propostas educacionais. Tendo como objetivo descrever a realidade encontrada na Escola Municipal de Educação Básica Maria Aparecida Amaro de Souza, no que diz respeito à relação das mídias no ensino aprendizagem, na pratica dos docentes das séries iniciais do ensino fundamental (primeiro, segundo e terceiro ano) e os benefícios para o processo ensinoaprendizagem. Considerando-se como especificidade identificarem-se as facilidades e dificuldades para a incorporação das mídias no processo ensino-aprendizagem, Também, descrever os benefícios que as mídias trouxeram para a aprendizagem cognitiva, observados durante a pesquisa de campo e nas revisões do estudo bibliográfico.

Numa perspectiva de formação dos cidadãos a escola permite a interação entre 0 processo de ensino aprendizagem com as mídias e os instrumentos tecnológicos que estão á disposição dos docentes e dos discentes. A educação, ao longo dos anos, tem incorporado em suas práticas pedagógicas várias mídias que ajudam os professores e alunos no processo ensino aprendizagem, enriquecendo as aulas e facilitando a comunicação didática.

Diante das novas exigências, a escola necessita oferecer aos alunos serviços de qualidade, logo os professores precisam ajustar a sua didática as novas realidades da sociedade, do conhecimento, do aluno, dos novos meios de comunicação, 0 profissional precisa estar se aprimorando, se reciclando perante as novas tecnologias, o professor tem que ter uma visão concreta da linguagem informacional e dos meios de informação bem como habilidades com as mídias e multimídias.

Nossa perspectiva criamos nossa problemática de investigação em forma de pergunta porque queremos saber: como os professores estão incorporando as mídias com as novas Tecnologias no processo de ensino-aprendizagem das turmas dos $1^{\mathrm{a}} \mathrm{S}, 2^{\mathrm{a}} \mathrm{s}$ e $3^{\mathrm{a}} \mathrm{s}$ do ensino fundamental da Escola Municipal de Educação Básica Maria Aparecida Amaro de Souza?

Porque queremos saber quais as mídias que estão sendo utilizadas nas praticas educativas nas turmas involucrada. E em sequencia criamos nosso objetivo geral: analisar como os professores estão incorporando as mídias com as novas Tecnologias no processo de ensino-aprendizagem das turmas dos $1^{\circ} \mathrm{S}, 2^{\circ} \mathrm{S}$ e $3^{\circ} \mathrm{S}$ do ensino fundamental da Escola Municipal de Educação Básica Maria Aparecida Amaro de Souza. Com base nisso construímos nossos objetivos específicos: descrever as mídias que estão sendo desenvolvidas nas turmas dos $1^{\circ} \mathrm{S}, 2^{\circ} \mathrm{s}$ e $3^{\circ} \mathrm{s}$ do ensino fundamental da Escola Municipal de Educação Básica Maria Aparecida Amaro de Souza; identificar as facilidades dos educadores para trabalhar com as 
mídias e as tecnologias nas turmas $1^{\circ} \mathrm{s}, 2^{\circ} \mathrm{s}$ e $3^{\circ} \mathrm{s}$ do ensino fundamental da Escola Municipal de Educação Básica Maria Aparecida Amaro de Souza; identificar as dificuldades encontradas pelos educadores para trabalhar com as mídias e as tecnologias nas turmas $1^{\circ} \mathrm{S}, 2^{\circ} \mathrm{s}$ e $3^{\circ} \mathrm{s}$ do ensino fundamental da Escola Municipal de Educação Básica Maria Aparecida Amaro de Souza.

Com as constantes mudanças que vêm ocorrendo na sociedade, muito têm sido as exigências de transformação postas à Educação. A fim de atender às demandas do mundo moderno, a mesma têm assumido funções mais complexas, dentre as quais está á implementação das novas tecnologias no contexto escolar para que seja possibilitado aos educandos o domínio destes recursos. Nesta perspectiva buscamos uma analise de como os professores estão preparados para que aconteça essa mudança no espaço escolar ou de que forma já estão avançando nesta nova etapa educacional.

Como a cada dia que passa a nova tecnologia vai adquirindo novos espaços na cultura, no conhecimento, lazer e em geral na vida do ser humano. Percebe-se que atualmente cresce 0 número de famílias que possuem essas mídias em suas residências. Assim essas novas ferramentas vêm auxiliando pais e alunos no novo jeito de aprender e ver o mundo. Portanto quando aprendemos a lidar com elas, novos horizontes se abrem para a vida do ser humano. Assim aconselhamos o uso das mídias que permitem cada vez mais pesquisar, simular situações, descobrir novos conceitos, lugar e ideias. Portanto a educação tem que ir a busca das novas tecnologias porque o nosso educando convive com essas tecnologias, e a escola tem que inovar, para que as aulas se tornem atrativas e motivem os mesmos em aprender, para isso o professor tem que estar atualizado e habilitado. Deste modo os professores e os gestores tornam-se os principais responsáveis por efetivar planejamentos pedagógicos que utilizam as tecnologias que a escola disponibiliza. Ou seja, professor precisa ter bem claro os objetivos e como usar essas ferramentas para que tenha um bom desempenho e consiga chegar ao ensino/aprendizagem esperado.

Desta forma, destacamos que no ensino laprendizagem tem novos moldes, não somente a mera transmissão de conhecimento acadêmico, mas, sim a integração de forma significativa de todas as tecnologias, sendo que isso se torna um salto qualitativo no processo educacional.

\section{2.-Desenvolvimento.}

2.1.-A concepção dos educadores sobre a influência da mídia na educação no processo de ensino aprendizagem.

A mídia é um fator fundamental na vida da sociedade, sem ela a sociedade fica aquém da realidade. Assim, os meios eletrônicos de comunicação são as bases para um compartilhamento de idéias e também, processo importante na construção de projetos colaborativos. Dos avanços tecnológicos nasceu a mídia. Neste sentido, ela 
está incluída na educação, sociedade e escola. Este é um tema polêmico, pois muitos afirmam que a mídia pode ser uma influência negativa, já outros acreditam que a mídia deve ser de interesse de professores, pais, alunos, pois ela pode melhorar a educação (Moore e Kearsley, p. 58, 2013).

Para Kenski (2010), a escola representa na sociedade moderna o espaço de formação não apenas das gerações jovens, mas de todas as pessoas. Em um momento caracterizado por mudanças velozes, as pessoas procuram na educação escolar a garantia de formação que Ihes possibilite o domínio de conhecimento e melhor qualidade de vida.

De acordo com Porto ( 2009) a grande questão para a escola é a construção de um projeto pedagógico que permite a formação dos cidadãos plenos. Nele a tecnologia estará inserida, de forma adequada aos objetivos, como uma das maneiras de proporcionar a professores e alunos uma relação profunda com o conhecimento. 0 foco para a mudança é desenvolver alunos criativos, inovadores e corajosos. Alunos e professores que busquem mais, que relacionem mais, que saiam do previsível do padrão.

\section{2.-Bases teóricas.}

Essa educação escolar, no entanto, aliada ao poder governamental, detém para si 0 poder de definir e organizar os conteúdos que considera socialmente válidos para que as pessoas possam exercer determinadas profissões. Pois de acordo com Belloni (2009) a introdução das máquinas inteligentes em todas as esferas da vida social é incontestável: no trabalho e no lazer; nas esferas publicas e privada. As principais instituições sociais foram sendo transformadas por mídias que nos dias de hoje são tão rápidas as mudanças que vem sendo compreendidas na expressão tecnologia de informação e comunicação (TIC ).

Belloni (2009) acredita que para enfrentar estes desafios o professor terá que aprender a trabalhar em equipe e a transitar com facilidade em muitas áreas disciplinares. Será "necessário quebrar o isolamento da sala de aula convencional e assumir funções coletivas e diferenciadas" (p. 29).

Para (Straub, 1997, p. 37), pode-se afirmar que a capacitação dos professores é um dos princípios fundamentais para apoiar a integração da tecnologia na escola. 0 aperfeiçoamento constante dos profissionais da educação é necessário para que aconteça 0 processo ensino-aprendizagem. Os profissionais utilizando as mídias tecnológicas mediante a uma concepção construtivista é algo que possa ser trabalhado em vários momentos de forma coletiva.

\section{3.-Mídias no ensino aprendizagem.}

Em geral as escolas se preocupam com o conhecimento intelectual, mas na atualidade constatamos que tão importante como as ideias e 0 equilíbrio emocional, 0 desenvolvimento de atitudes positivas diante de si mesmo e dos outros, 0 aprender 
a colaborar a viver em sociedade, em grupo, a gostar de si e dos demais. Para tanto é necessário sensibilizar e capacitar os professores para ações inovadoras, para tomar mais a iniciativa, explorar novas possibilidades nas suas atividades didáticas na sua carreira na sua vida (Moran, 2009, p.133). Neste ponto de vista 0 autor Moran (2009), afirma que a sala de aula precisa ser confortável com boa acústica e tecnologias, das simples até as sofisticadas. Uma classe, hoje precisa ter ao seu alcance aparelhos de vídeo, DVD, projetor multimídia e no mínimo, um ponto de internet para acesso a sites em tempo real pelo professor ou pelos alunos, quando necessário. De forma que, para ter uma educação de qualidade deve-se ter um computador em cada sala, com projetor multimídia, para que tenha um melhor desenvolvimento no trabalho do professor e alunos. Straub (1997) assevera que "diante dos processos de globalização, o computador é considerado uma ferramenta para a capacidade de aprender, dar sentido a informação e até de tomada de decisões." Consideramos que este possibilite novas estratégias de ensino aprendizagem, como ferramenta capaz de aumentar a motivação, concentração e autonomia permitindo ao aluno a manipulação da representação e organização do conhecimento (p. 27). Assim, para Oliveira (2009), as mídias na educação é uma temática que até os dias de hoje é estudada e discutida com pouca ou nenhuma ênfase nos cursos de formação inicial de professores, tornando-se uma questão recorrente nas formações continuadas dos profissionais da educação. E diante disso, a educação escolar precisa compreender e incorporar as novas linguagens desvendar seus códigos dominar as possibilidades e expressão e as possíveis manipulações. É importante educar para uso democrático mais progressista e participativo das tecnologias que facilitem a educação dos indivíduos. (MORAN, 2000, p. 26).

\section{3.-Método.}

Este trabalho de investigação tem um enfoque qualitativo conforme a ideia de (Richardson, 2011 p. 79) "A abordagem qualitativa de um problema, além de ser uma opção do investigador, justifica-se, sobretudo, por ser uma forma adequada para entender a natureza de um fenômeno social". Este estudo de investigação tem um enfoque não experimental e descritivo3.1. Descrição da população e amostra.

A população é composta por seis educadores regentes atuantes nos primeiros, segundos e terceiros anos do Ensino Fundamental da referida escola municipal, totalizando oito educadores e também totalizando uma media de 150 educandos considerando-se amostra por acessibilidade visto que este tipo de amostragem não tem representação estatística conforme diz (Cruz, 2011, p. 21), "Ao invés de estatísticas, regras e outras generalizações, ela trabalha com descrições, comparações, interpretações e atribuição de significados possibilitando investigar valores, crenças, hábitos, atitudes e opiniões de indivíduos ou grupos".

\section{2.-Técnicas e instrumentos de coleção de dados.}


Os dados foram coletados através de observações sistemáticas com o apoio de um guia de observação e aplicação de questionários com questões semiestruturadas, destinadas aos adolescentes das turmas do primeiro, segundo e terceiro ano do Ensino Fundamental. As questões abordarão os objetivos apresentados no trabalho.

\section{4- Discussões.}

Realizou-se a pesquisa com oito educadores que atuam nas seis turmas das séries iniciais, primeiro, segundo e terceiro anos do Ensino Fundamental. Apontando que dois Educadores não entregaram e não responderam totalizando seis entrevistados.

1.-Tabela de classificação de resposta.

\begin{tabular}{|c|c|}
\hline 1.-0 que é mídia para você? & $\begin{array}{l}\text { Conclusão: } \\
\text { De acordo das respostas dos educadores nota-se que, } \\
0 \text { E2, E5 e E6 ressaltaram-se, que as mídias são } \\
\text { ferramentas tecnológicas, e E1 e E3, citam alguns } \\
\text { itens como sendo mídias e o E4 somente diz que são } \\
\text { recursos para desenvolver qualquer trabalho, mas não } \\
\text { define quais. }\end{array}$ \\
\hline $\begin{array}{l}\text { 2.-Quais são as mídias que a } \\
\text { escola oferece ao educador, } \\
\text { que possam ser utilizadas em } \\
\text { suas metodologias durante o } \\
\text { desenvolvimento da aula? }\end{array}$ & $\begin{array}{l}\text { Conclusão: Por unanimidade responderam que } \\
\text { utilizam várias mídias como parte do processo } \\
\text { metodológico. Observa-se que os educadores tem } \\
\text { uma boa aproximação das mídias convencionais } \\
\text { sendo elas ferramentas comuns da sala de aula com } \\
\text { as novas tecnologias de comunicação. }\end{array}$ \\
\hline $\begin{array}{l}\text { 3.-Quais são as mídias que } \\
\text { você emprega em suas aulas? }\end{array}$ & $\begin{array}{l}\text { Conclusão: Os educadores foram unânimes em } \\
\text { afirmar que estão incorporando as mídias em suas } \\
\text { metodologias durante } 0 \text { desenvolvimento de suas } \\
\text { aulas. Mas não especificam. }\end{array}$ \\
\hline $\begin{array}{l}\text { 4.-Em sua opinião, qual o grau } \\
\text { de importância das mídias no } \\
\text { processo ensino I } \\
\text { aprendizagem considerando } \\
\text { uma nota de zero a dez? } \\
\text { Comente: }\end{array}$ & $\begin{array}{l}\text { Conclusão: } \\
\text { Analisando as respostas do questionário aplicado aos } \\
\text { docentes, constata-se que quatro educadores } \\
\text { consideram a nota dez no grau de importância das } \\
\text { mídias no processo ensino aprendizagem. }\end{array}$ \\
\hline $\begin{array}{l}\text { 5.-0 que você sugere para } \\
\text { melhorar a incorporação das } \\
\text { mídias envolvendo as } \\
\text { tecnologias no processo de } \\
\text { ensinol aprendizagem? }\end{array}$ & $\begin{array}{l}\text { Conclusão: Tivemos aqui algumas sugestões para } \\
\text { melhorar a incorporação das mídias envolvendo as } \\
\text { tecnologias chega-se a conclusão de que os } \\
\text { educadores têm ideias de como melhorar o processo } \\
\text { de ensino aprendizagem. Sugerindo uma organização } \\
\text { no horário, tempo para pesquisar e preparar material e } \\
\text { etc... }\end{array}$ \\
\hline $\begin{array}{l}\text { 6.Queconhecimento/benefícios } \\
\text { os alunos revelam quando } \\
\text { estão envolvidos em uso das } \\
\text { tecnologias de comunicação? }\end{array}$ & $\begin{array}{l}\text { E1 - Desenvolve o raciocínio lógico através da atração } \\
\text { que as mídias provocam. } \\
\text { E2 - Aprendizagem de forma mais prazerosa. } \\
\text { E3 - Desenvolve bastante o cognitivo através da } \\
\text { visualização, audição, movimentação, pois para alguns } \\
\text { educandos só tem acesso a esses aparelhos na } \\
\text { escola. } \\
\text { E4 - As crianças destacam conhecimentos prévios, }\end{array}$ \\
\hline
\end{tabular}




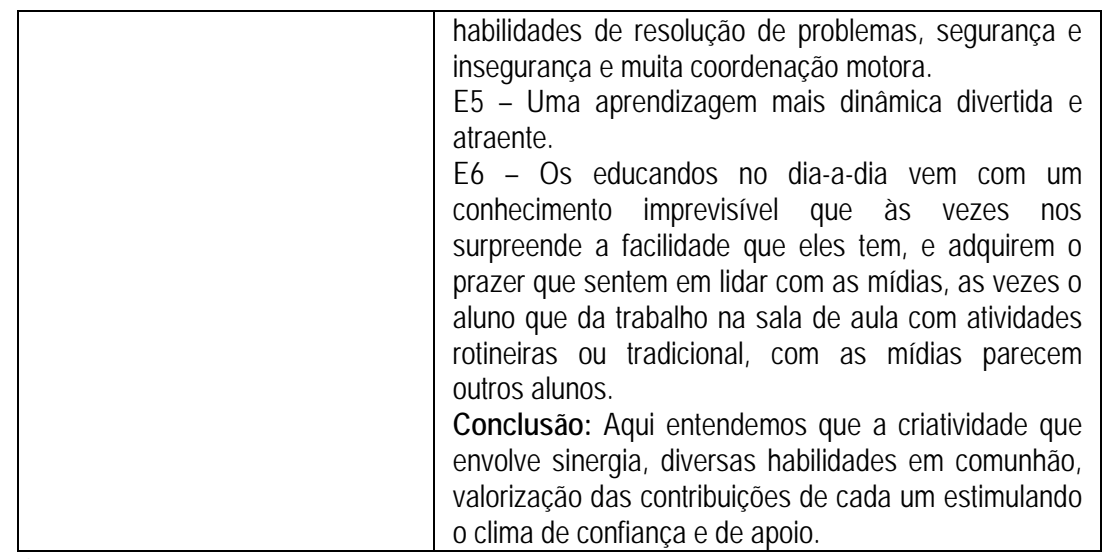

Construção própria.

\section{5.-Conclusão.}

Com base na problemática, objetivos da pesquisa, nos dados obtidos e no referencial teórico, foi-se possível chegar as seguintes considerações.

De acordo com estudos bibliográficos e os relatos de experiências dos educadores e com a observação feita durante a pesquisa nas turmas do primeiro, segundo e terceiro anos do Ensino Fundamental da Escola Municipal de Educação Básica Maria Aparecida Amaro de Souza, pode-se notar que as mídias são consideradas importantes, para o ensino aprendizado.

Através da pesquisa podem-se identificar as facilidades, as dificuldades da incorporação das mídias na pratica docente e possibilitou-se a descrição dos benefícios da aprendizagem observada nas respostas dos questionários e na pesquisa de campo. Durante a pesquisa se observa que as atividades desenvolvidas com as mídias tecnológicas com os educandos do primeiro, segundo e terceiro ano do ensino fundamental acontecem com organização com um cronograma de horário. Já as mídias convencionais da sala de aula acontecem diariamente de acordo com 0 planejamento do professor.

Tendo em vista a incorporação das mídias no ensino aprendizado sendo destacado pelos autores e os educadores pesquisados que a mídia é um recurso pedagógico que auxilia 0 educador em suas práticas docentes. No entanto observa-se que todos os educadores das turmas pesquisadas e observadas da escola municipal faz 0 uso das tecnologias de comunicação realizando assim uma conexão com as mídias e os conteúdos estudados.

Entende-se que é de fundamental importância oportunizar e valorizar os educadores que vem solicitando novas maneiras de se construir o conhecimento a partir do crescente acesso as diversas mídias. Pois acreditamos que a criatividade e as contribuições das mídias tecnológicas nas praticas docentes geram uma nova 
metodologia sendo aliada e correspondida a sociedade globalizada. Cabe ao educador, planejar, organizar suas praticas pedagógicas dentro de um sistema, onde deva selecionar as técnicas e as estratégias mais adequadas para a situação de ensino viabilizando com a elaboração de projetos que estejam ligados aos conteúdos, e ao Plano Politico Pedagógico da Escola.

Através do uso das mídias tecnológicas (computador, vídeo, data show) o educando terá a oportunidade de usar, tocar, visualizar, ouvir vivenciar experiências diferentes. Construirá assim o seu conhecimento escolar e desenvolverá no indivíduo a integração social.

Ao desenvolver as atividades com a incorporação das mídias tecnológicas em sala de aula manifesta-se um grande beneficio no ensino aprendizado. Destacando-se a favorecer um aprendizado prazeroso com dinâmicas variadas e bastante ludicidade. Diante disso cabe ao educador ser criativo, flexível estabelecendo uma relação entre as ferramentas e os conteúdos, tornando-se um aprendizado de sucesso. A relação entre ferramenta e conteúdos, desenvolve o cognitivo, o raciocínio lógico e a coordenação motora do educando trazendo mais segurança e confiança e prazer ao desenvolver as atividades. 0 uso das mídias tecnológicas possibilita a interação entre os educandos ao mesmo tempo em que trabalha a pratica educacional individualmente proporcionando maior interesse e compreensão no desenvolvimento das atividades. Jogando o educando se concentra e aprende com alegria e prazer se socializar com o colega onde 0 educando tem que socializar a ferramenta e muitas vezes esperar a sua vez e também saber passar a vez para o próximo. Muitas vezes saber se controlar em ficar em silêncio para que todos possam ouvir e visualizar.

Cabe também ao educador, ao planejar e organizar sua prática pedagógica, selecionar as técnicas e as estratégias mais adequadas para a situação de ensino, tendo como objetivo maior a formação do processo de ensino aprendizagem. Quando se desenvolve um conteúdo utilizando as mídias tecnológicas, o interesse e a curiosidade do educando torna-se maior e com mais facilidade na compreensão.

Diante disso, percebem-se os grandes benefícios que a mídia tecnológica desenvolve no processo ensino aprendizagem dos educandos dos anos iniciais da escola municipal, ainda que a utilização dessas ferramentas aconteça de maneira fragmentada, entre os benefícios estão a facilidade de se comunicar, a socialização, a autonomia na realização das atividades, coordenação motora, concentração, atenção, desenvolvimento de estratégias de jogo, agilidade, respeito mútuo, autocontrole, alegria, espírito de equipe, autoestima e o cognitivo, entre outros aspectos abordados em relação aos conteúdos da proposta curricular.

Como nossa sociedade vem se desenvolvendo com muita rapidez no processo tecnológico, o educando já vem para escola influenciada apela atualidade, facilitando assim o manuseio das ferramentas no processo ensino aprendizado. Portanto muitas vezes o educador não tem esse conhecimento e as novas habilidades de manusear 
as mídias tecnológicas, tornando-se dificultoso no desenvolvimento do processo ensino aprendizagem.

Considera-se uma das dificuldades apontadas pelos educadores a falta de orientação para que possam estar incluindo as mídias tecnológicas no planejamento a ser desenvolvido pelos mesmos.

Neste sentido esta realidade nos remete a problemática da formação acadêmica dos educadores e coordenadores pedagógicos que já vieram com a formação pedagógica tecnicista e apresentam a dificuldade em manusear essas ferramentas tecnológicas. É assim sem estar preparado passam essa pedagogia adiante apresentando dificuldade em relacionar-se com as mídias tecnológicas.

De acordo com os dados coletados, entendemos que é de fundamental importância oportunizar os educadores a atualizar-se de acordo com a sociedade. Pois se observou que é de grande dificuldade que o educador encontra em atualizar-se com as novas tecnologias. No entanto não tem disponibilidade em seu horário, também porque não tem acessibilidade a tendência das últimas horas.

Portanto a capacitação do profissional é de suma importância ao processo ensino aprendizagem para tornar 0 momento de ensino em algo agradável, prazeroso, divertido e ao mesmo tempo rico em conhecimento e relacionando-se aos benefícios do educando.

Finalmente 0 estudo nos mostra a importância de que 0 educador tenha 0 mínimo de noções básicas das mídias, e por tanto, que conheça aos seus educandos, para que possa elaborar um bom planejamento usando uma boa metodologia com os conteúdos necessários para desenvolver um excelentíssimo processo ensino aprendizado.

\section{Referências}

Belloni, M.L. (2009). Crianças e mídias no Brasil: cenários de mudança. Florianópolis: Atlas.

Kenski, V.M. (2010). Tecnologia e as Alterações no Espaço e Tempo de Ensinar e Aprender. São Paulo: Papirus.

Moore. M.G, Kearsley. M. ( 2013). Educação a distância: sistemas de aprendizagem on-line. 3. ed. São Paulo. Ed. Cengage Learning.

Moran, J.M. (2009). Mudar a forma de ensinar e aprender com tecnologia: Transformar as aulas em pesquisa e comunicação presencial- virtual. $16^{\circ} \mathrm{ed}$. Campinas: Papirus.

Oliveira, D.P. (2009). Rebouças; Planejamento Estratégico. 26ª ed, São Paulo: Atlas. 
Porto, A. (2009). Um olhar comprometido com o ensino. Belo Horizonte: FAPI.

Prado, M.E. B.B. (2010). Integração de Mídias e a Reconstrução da Prática Pedagógica., Rio de Janeiro: PUC.

Straub, K., Brenner, W. (1997). Testing the technology acceptance model across multures: a three contry study. Information \& Management, v.33, 1-11. 